\title{
Benedito Medrado
}

\author{
Universidade Federal de Pernambuco
}

Jorge Lyra

Instituto PAPAI

\section{Por uma matriz feminista de gênero para os estudos sobre homens e masculinidades}

\begin{abstract}
Resumo: Este artigo tem o objetivo de contribuir para os estudos e pesquisas sobre homens e masculinidades, apresentando um marco conceitual de gênero, a partir de uma matriz que dialoga com produções feministas e se organiza em quatro eixos: 1) o sistema sexo/gênero; 2) a dimensão relacional; 3) as marcações de poder; e 4) a ruptura da tradução do modelo binário de gênero nas esferas da política, das instituições e das organizações sociais. Para tanto, dialogamos com produções contemporâneas que adotam "gênero" como categoria analítica e se baseiam em referenciais teóricos distintos, mas têm em comum (e se autodefinem a partir de) uma perspectiva feminista crítica. A partir dessa matriz, traz-se uma análise dos estudos sobre os homens e masculinidades no campo da saúde, sexualidade e reprodução, destacando a necessidade de abrir espaço para novas construções teóricas que resgatem o caráter plural, polissêmico e crítico das leituras feministas.
\end{abstract}

Palavras-chave: homens; masculinidades; teoria feminista; feminismo.

Copyright (c) 2008 by Revista Estudos Feministas.

' Conforme Débora DINIZ e Paula FOLTRAN, 2004; e Karen GIFFIN, 2005.

2 "Maldito" especialmente no sentido daquele que "traz infelicidade, incomoda, aborrece; funesto, detestável, infeliz, enfadonho" (HOUAISS, 2001).

3 Conforme Enrique GOMÁRIZ, 1992; e Margareth ARILHA, Sandra UNBEHAUM e Benedito MEDRADO, 1998.

${ }^{4}$ Alguns dos trabalhos produzidos nessa época: Tim CARRIGAN,

\section{Situando nossa argumentação}

Nos últimos 40 anos, em que os estudos de gênero se consolidaram na produção acadêmica ocidental, especialmente no campo das Ciências Humanas e Sociais, foram produzidos trabalhos - a maioria por mulheres pesquisadoras $^{1}$ - que discutem os homens e o masculino como faces malditas ${ }^{2}$ das relações que produzem desigualdades sociais e subordinam as mulheres. ${ }^{3}$

As produções sobre as masculinidades, como objeto de estudo propriamente dito, por outro lado, têm início no final da década de 1980, ${ }^{4}$ a partir de trabalhos produzidos de maneira ainda pouco sistemática, com concentração 
Robert CONNELL e John LEE, 1985; KAUFMAN, 1987; Michael KIMMEL, 1987; entre outros.

${ }^{5}$ Conforme Benedito MEDRADO e Jorge LYRA, 2002; e Juan Guillermo FIGUEROA-PEREA, 2003.

- Dentro da profícua produção nessa área, citamos R. W. CONNELL, 1995a e 1995b; Miriam GROSSI, 1995; ARILHA, UNBEHAUM, MEDRADO, 1998; Pierre BOURDIEU, 1998.

${ }^{7}$ Robert Connell submeteu-se à cirurgia para 'mudança de sexo' e, mais recentemente, vem publicando ou reeditando suas produções com assinatura de Rayween (seu nome atual) ou simplesmente R. W. Connell.

8 CONNELL, HEARN e KIMMEL, 2005, p. 7. em autores específicos e sem necessariamente se desdobrarem em uma discussão teórica, epistemológica, política e ética ampla e consistente sobre o tema. ${ }^{5}$

Mais recentemente, especialmente a partir da segunda metade da década de 1990, tem sido produzido um conjunto de obras que buscam sistematizar produções diversas de modo a possibilitar o aprofundamento almejado. ${ }^{6}$ Buscando produzir uma organização dessas produções, especialmente aquelas publicadas entre 1995 e 2002, Robert (agora Rayween) Connell, ${ }^{7}$ Jeff Hearn e Michael Kimmel publicam, em 2005, o Handbook of Studies on Men and Masculinities, no qual abordam o que eles denominam "desenvolvimento do campo de pesquisas sobre masculinidades", focalizando o modo como os estudos e pesquisas têm construído esse campo: desde um olhar "mais amplo e global" até a expressão "mais íntima e pessoal". ${ }^{8}$ Este, assim denominado, "campo" é, segundo esses autores, constituído a partir de produções que apresentam objetos distintos:

1. a organização social das masculinidades em suas "inscrições e reproduções" locais e globais;

2. a compreensão do modo como os homens entendem e expressam "identidades de gênero";

3. as masculinidades como produtos de interações sociais dos homens com outros homens e com mulheres, ou seja, as masculinidades como expressões da dimensão relacional de gênero (que apontam expressões, desafios e desigualdades);

4. a dimensão institucional das masculinidades, ou seja, o modo como as masculinidades são construídas em (e por) relações e dispositivos institucionais.

Os argumentos desenvolvidos neste artigo situam-se entre o terceiro e o quarto níveis de análises definidos acima, na medida em que consideramos a Saúde Pública como um campo de relações interpessoais e institucionais, que se organizam em dispositivos e relações de poder e que marcam posições de sujeito e modos de ser, de saber e de fazer, como desenvolvemos mais adiante.

Nosso objetivo é contribuir para as reflexões feministas sobre homens e masculinidades, apresentando um marco conceitual de gênero, no contexto da saúde pública, a partir de uma matriz que se organiza em quatro eixos: 1) o sistema sexo/gênero; 2) a dimensão relacional; 3) as marcações de poder; e 4) a ruptura da tradução do modelo binário de gênero nas esferas da política, das instituições e das organizações sociais. Para tanto, dialogamos com produções contemporâneas que adotam "gênero" como 
9 Entre as obras que deram sustentação a esses argumentos, destacamos especialmente Teresita BARBIERI, 1992; María Jesús IZQUIERDO 1994 e 2006; Joan SCOTT, 1995; Donna HARAWAY, 1995; e Verena STOLCKE, 2004.

10 Baseamos esses argumentos especialmente em produções de Maria Betânia ÁVILA, 2003; e FIGUEROA-PEREA, 2005.

11 Estela AQUINO, 2006.

${ }^{12}$ AQUINO, 2006, p. 128. categoria analítica e baseiam-se em referenciais teóricos distintos, mas têm em comum (e se autodefinem a partir de) uma perspectiva feminista crítica. ${ }^{9}$

Esta proposta decorre de nossa preocupação teórica e política com relação à produção acadêmica e/ou militante e suas repercussões na formulação e implementação de políticas públicas em saúde a partir do enfoque de gênero. ${ }^{10}$

Preocupação semelhante orienta as reflexões de Estela Aquino," em seu artigo intitulado "Gênero e saúde: perfil e tendências da produção científica no Brasil". Segundo essa autora, as reflexões teóricas e epistemológicas sobre as relações de gênero e saúde no campo da Saúde Coletiva ainda são escassas e a incorporação da abordagem de gênero na epidemiologia tem sido lenta e enfrenta dilemas teóricos que geram obstáculos ao uso de "gênero" como categoria analítica e não apenas como substituição da variável "sexo". Dificuldade maior é apontada por essa autora à incorporação de outras categorias sociais, tais como "raça/etnia" e "idade". Só mais recentemente e, de "distintas formas", segundo a autora, é que as intersecções de raça/etnia e idade/geração são incorporadas ao debate de saúde, classe e gênero.

\section{Gênero e saúde: "distintas formas" objetos}

Quando Aquino destaca as "distintas formas", ela está se referindo particularmente à interdisciplinaridade no campo da Saúde Coletiva. De todo modo, observa que a adoção da "abordagem de gênero como construção cultural e recorrendo a estratégias qualitativas de pesquisa" 12 está em maior medida na produção das ciências sociais em saúde, embora segundo ela, o principal paradigma e categoria explicativa tem sido ainda 0 marxismo e as determinações sociais de classe. Não há (ou há muito pouca) interface com os outros determinantes sociais da saúde.

Nesse trabalho, Aquino faz um amplo e importante mapeamento do debate brasileiro sobre gênero e saúde, no qual os principais temas foram reunidos, por ela, em cinco subgrupos: 1) reprodução e contracepção; 2) violência de gênero, e suas variações (tais como violência doméstica, familiar, conjugal e sexual); 3) sexualidade e saúde (com ênfase nas DST/Aids); 4) trabalho e saúde (incluindo o trabalho doméstico e o trabalho noturno); e 5) outros temas emergentes ou pouco explorados como o envelhecimento e a saúde mental. Essa diversidade de temas ganha contornos ainda mais diversos quando observamos a pluralidade de enfoques da Saúde Pública em suas "distintas formas" ou 
${ }^{13}$ AQUINO, 2006, p. 128.

14 IZQUIERDO, 1994.

\footnotetext{
${ }^{15}$ SABO, 2000.

16 Conforme Gayle RUBIN, 1986; HARAWAY, 1995 e 2004; Judith BUTLER, 2003a e 2003b; e RUBIN e BUTLER, 2003.

${ }^{17}$ Enrique Gomáriz, por exemplo, em seu artigo publicado em 1992, faz uma "retrospectiva" histórica das produções sobre gênero e, de certo modo, acaba por realizar uma leitura quase evolucionista das produções que partem dos "estudos sobre mulheres" para os "estudos de gênero", em que estes últimos não guardariam nenhuma referência do contexto histórico em que os primeiros emergem (GOMÁRIZ, 1992).

${ }^{18}$ Conforme Anette GOLDBERG, 1989; Cynthia SARTI, 2004; Ana Alice COSTA, 2005; e Lucila SCAVONE, 2007.
}

diferentes subáreas. A subárea de Planejamento e Políticas de Saúde foi, segundo a autora, a que menos incorporou a abordagem de gênero. Aquino ressalta ainda que

\begin{abstract}
Os temas "nobres" desta subárea, tais como modelos de atenção, controle social e movimentos sociais, relações de poder e estrutura de saúde, têm tido pouca influência da perspectiva de gênero. Isso já havia sido constatado entre as ciências humanas pela menor penetração desse enfoque nas ciências políticas, comparativamente à antropologia, à sociologia e à história. ${ }^{13}$
\end{abstract}

O diferencial dessas produções são os estudos recentes de avaliação em saúde, que introduziram "gênero" como categoria analítica, porém, segundo a autora, voltando-se prioritariamente a estudos sobre a saúde das mulheres. Ou seja, estes parecem ainda se orientar pelo modelo binário masculino-feminino e adotam a substituição de gênero por sexo, privilegiando, muitas vezes de modo exclusivo, as experiências das mulheres.

Nesse processo, nossa produção situa-se em consonância com produções recentes que buscam resgatar a importância das contribuições do feminismo, as quais se vêm perdendo ao longo da história com o uso indiscriminado e 'despolitizado' do conceito de "gênero", ou seja, de seus "usos e abusos", como define María Jesús Izquierdo. ${ }^{14}$

Assim, postulamos a necessidade de sistematização crítica desse debate, especialmente no que se refere ao trabalho voltado aos homens e masculinidades no campo dos direitos reprodutivos, particularmente no contexto das políticas públicas. ${ }^{15}$ Para tanto, é necessário reconhecer, por um lado, que 1) as teorias de gênero que dialogam mais diretamente com o feminismo constituem um campo teórico-epistemológico em constante desenvolvimento e revisão ${ }^{16}$ e, por outro, que 2) os estudos de gênero, embora por vezes sejam considerados uma espécie de evolução do pensamento feminista, ${ }^{17}$ precisam resgatar os princípios críticos a partir dos quais foram forjados.

\subsection{Por uma leitura feminista de gênero em saúde}

É importante reconhecer que, no âmbito dos movimentos sociais que se constituem e se desenvolvem a partir dos anos 1960, os movimentos de mulheres e feministas são considerados relevantes devido ao impacto que geraram sobre a conformação das instituições. ${ }^{18}$ Tanto no plano internacional como no plano brasileiro, a movimentação das mulheres em prol de uma sociedade 
19 Conforme HARAWAY, 1995; STOLCKE, 1998; AQUINO, 2006; e Evelyn FOX KELLER, 2006.

${ }^{20}$ SARTI, 2004.

${ }^{21}$ LYRA, 1997.

22 Conforme GOLDBERG, 1989; BARBIERI, 1992; IZQUIERDO, 1994; e SCOIT, 1995.

${ }^{23}$ CORREA e VIANNA, 2006, p. 10.

24 Ver, por exemplo, Linda NICHOLSON, 2000; e Silvana MARIANO, 2005.

${ }^{25} \mathrm{Em}$ sua tese de doutoramento, intitulada Não basta ser mulher, tem de ter coragem: uma etnografia sobre gênero, poder, ativismo feminino popular e o campo político feminista de Recife - $P E$, Alinne Bonetti traz contribuições também importantes para esse debate (BONETTI, 2007). Ver também Claudia COSTA, 2002; MARIANO, 2005; e Adriana PISCITELLI, 2002 e 2004. mais justa tem levado a propostas de mudanças nas condições de vida de homens e mulheres. Ao mesmo tempo, essa movimentação vem constituindo novos sujeitos (mais complexos) e gerando também uma revisão dos fundamentos que têm orientado as ciências, particularmente humanas e sociais, e cada vez mais as ciências da natureza e da saúde. ${ }^{19}$

Em artigo publicado nesta revista, intitulado "O feminismo brasileiro desde os anos 1970: revisitando uma trajetória", Cynthia Sarti20 afirma que, em nosso país, as produções teóricas e políticas feministas se consolidam na década de 1970 a partir de duas tendências. Uma delas tinha como foco o mundo privado ou, nas palavras da autora, o "terreno fluido da subjetividade". Essa tendência caracterizou-se especialmente pelo interesse em grupos de estudos, de reflexão e de convivência. A segunda tendência, que se tornou mais expressiva, voltava-se para a atuação pública das mulheres, tendo como foco questões relativas ao trabalho, ao direito, à saúde e à redistribuição de poder entre homens e mulheres. Esta foi, segundo Sarti, a corrente que posteriormente buscou influenciar as políticas públicas em nosso país, empregando canais institucionais criados dentro do próprio Estado, no período da redemocratização dos anos 1980.

A partir da década de 1980, como abordado em estudo anterior, ${ }^{21}$ a produção teórica e política do feminismo tem sido múltipla, albergando diferentes tendências e evidenciando transformações. ${ }^{22}$ Porém, assumiu-se no Brasil a perspectiva internacional, aparentemente hegemônica, de os estudos feministas não mais discutirem sobre a mulher, mas sobre as relações de gênero, não obviamente sem controvérsias, pois, como apontam Sônia Corrêa e Adriana Vianna, na "dinâmica da militância feminista ainda existe grande resistência no que se refere a abrir mão deste 'patrimônio', ou seja, do capital político construído ao redor da categoria "mulher", associada diretamente ao seu potencial de representação". ${ }^{23}$

Numa seara conceitual e política contemporânea, que se coloca inclusive para além do contexto da pesquisa acadêmica, observa-se um grande e profícuo debate sobre o sujeito político do feminismo. ${ }^{24}$ Não é este o objeto de reflexões deste artigo. ${ }^{25}$ Porém, podemos listar questionamentos que emergem em diferentes contextos, tanto acadêmicos como na militância política ou em produções híbridas (a grande maioria). Alguns desses questionamentos poderiam ser assim resumidos:

- a legitimidade do sujeito político mulher, construída pelos movimentos sociais, corre o risco 
de se esvaziar a partir da ampla mirada que 0 conceito de gênero produz?

- no campo dos estudos de gênero, qual deveria ser o foco das investigações e proposições decorrentes deste terreno tencionado?

- no campo da produção teórica feminista, quem pode, de fato e de direito, exercer, representar ou posicionar-se a partir do feminismo, considerando que foram as mulheres que se propuseram a modificar sua condição de existência e que a afirmação do sujeito político mulher também se fundamenta no protagonismo (de voz e atos) feminino?

- as relações mais igualitárias e democráticas entre homens e mulheres, para o feminismo, seriam, em última instância, uma utopia?

Estas são perguntas que nos alimentam e/ou nos são colocadas como desafios e que, de certo modo, ecoam em cada linha deste texto, porém ultrapassam seus limites e potencialidades. Talvez, essas questões ultrapassem os próprios limites do feminismo e sejam um problema cuja resposta deva incluir outros interlocutores.

No que se refere, particularmente, à construção do sujeito político mulher, Guacira de Oliveira nos traz uma preocupação importante sobre o risco que a homogeneização de um sujeito único (mulher) produz ao desconsiderar as diferentes inserções políticas das mulheres na sociedade. Segundo ela, "É um grande desafio para o nosso movimento [feminista] transpor os limites do pensamento político para além das identidades e abarcar a angústia de ser negra, ser indígena, ser lésbica, super-explorada no mercado de trabalho ou excluída dele". ${ }^{26}$ Em outras palavras, para ela, o feminismo precisa ser submetido a uma análise de gênero, em sua dimensão relacional do poder.

\begin{abstract}
Trata-se de realizar operações que sejam capazes de lidar com os nossos conflitos e contradições, de reconhecer os campos de força, referências e capacidades e enfrentar as desigualdades e hierarquias no próprio movimento feminista. A tarefa consiste em incitar processos de negociação e tradução políticas, desafiando o pensamento a superar a aritmética simples da soma entre diferentes forças políticas, para podermos chegar a resultados mais complexos. ${ }^{27}$
\end{abstract}

Esse desafio do movimento também é apontado por autoras como Verena Stolcke ${ }^{28}$, Judith Butler, ${ }^{29}$ Claudia Fonseca ${ }^{30}$ e Nancy Fraser, ${ }^{31}$ que alertam para o risco de 0 
${ }^{32}$ Cito a nota de rodapé elaborada por Teresita de Barbieri para chamar a atenção para o significado do uso da palavra "mulher" no singular ou no plural: "O emprego no singular ou plural não é teoricamente irrelevante, posto que mulher faz referência a uma essência feminina única (o eterno feminino), a-histórica, fundamentada em concepções biológicas e metafísicas. Por outro lado, mulheres expressa a diversidade e historicidade de situações em que se encontram as mulheres" (BARBIERI, 1992, p. 113, nota de rodapé 5 , tradução nossa).

${ }^{33}$ Nesse trabalho, Rubin discute criticamente referências fundantes da teoria social contemporânea, especialmente Marx, Engels, Levis-Strauss, Freud e Lacan (RUBIN, 1986).

${ }^{34}$ RUBIN, 1986, p. 37, tradução nossa.

${ }^{35}$ BARBIERI, 1992, p. 114 , tradução nossa. emprego da categoria "mulher" 32 incorrer em um retorno a um essencialismo que busca a 'mulher de verdade', aquela a partir da qual e para a qual se inscreve o feminismo. Por outro lado, alerta-se para a fragmentação da própria luta das mulheres, decorrente da adesão às políticas identitárias particulares, com uma defesa forte das diferenças (de sexo, de orientação sexual, de anatomia genital, de raça, de gênero e de subjetividade), cada vez mais presente em nossa sociedade, dificultando a demanda por uma redistribuição igualitária de poder e de justiça social.

Assim, sem ter aqui o objetivo de oferecer respostas ou modelos ou ainda fazer um amplo balanço das correntes epistemológicas, teóricas e políticas que têm definido o conceito de "gênero" como categoria analítica, destacamos, com base nas reflexões acima, pelo menos quatro componentes do marco conceitual que, em nossa perspectiva, auxiliam na formulação de uma matriz feminista para estudos sobre homens e as masculinidades. Esse marco conceitual estrutura-se em quatro eixos: 1) o sistema sexo/ gênero; 2) a dimensão relacional; 3) as relações de poder; e 4) a ruptura da tradução do modelo binário de gênero nas esferas da política, das instituições e das organizações sociais.

\section{Definindo um marco conceitual}

Gayle Rubin, antropóloga feminista, é uma das principais referências sobre o que se concebe como "sistema sexo/gênero". Em seu artigo "The Traffic in Women: Notes on the 'Political Economy' of Sex", publicado originalmente em $1975,{ }^{33}$ essa autora, referenciada por vários estudos posteriores, denomina o "sistema de sexo/gênero" como "o conjunto de disposições pelas quais uma sociedade transforma a sexualidade biológica em produtos da atividade humana, e pelas quais se satisfazem essas necessidades humanas transformadas". ${ }^{34}$

Assim, o primeiro exercício para definição de nosso marco conceitual consiste em reafirmar a necessidade de desnaturalizar as prescrições e práticas sociais atribuídas a (e incorporadas e naturalizadas por) homens e mulheres, consideradas marcações masculinas e femininas. Como observa Teresita de Barbieri,

[...] os sistemas de sexo/gênero são os conjuntos de práticas, símbolos, representações, normas e valores sociais que as sociedades elaboram a partir da diferença sexual anátomo-fisiológica e que dão sentido à satisfação dos impulsos sexuais, à reprodução da espécie humana e em geral ao relacionamento entre as pessoas. ${ }^{35}$ 
36 IZQUIERDO, 1994, p. 49, tradução nossa.

37 IZQUIERDO, 1994, p. 49, tradução nossa.

${ }^{38}$ Ver Elisabeth BADINTER, 1985.

${ }^{39}$ Ver Barbara BEATTY, 1989.

40 [...] "termo é uma unidade lingüística enquanto o conceito é a unidade do pensamento; não é um dado que procede da experiência, e sim da busca de explicações que requer a análise" [...] (Mario BUNGE, 1989, apud IZQUIERDO, 1994, p. 33, tradução nossa).
María Jesús Izquierdo adota também o conceito de "gênero" como categoria analítica para compreender desigualdades sociais. Essa autora considera que a desigualdade fundamental entre homens e mulheres reside nas formas como os seres humanos se relacionam na produção da sua existência, ou seja,

[...] a sociedade se acha estruturada em dois gêneros, - que produz e reproduz a vida humana, e o que produz e administra riquezas mediante a utilização da força vital dos seres humanos. Vemos que o setor produtivo da vida humana se organiza em condições de dependência com relação ao setor dedicado à produção da riqueza e à administração. ${ }^{36}$

Essa autora diferencia sexo e gênero, bem como desigualdades de gênero - distribuição desigual de poder em função do pólo produção/reprodução da vida e produção/administração de riquezas - e desigualdades de sexo - decorrentes do fato de essas atividades serem executadas por homens ou mulheres (machos y hembras, no original) -, desigualdades essas que podem, ou não, coincidir:

[...] em nossa sociedade o que se apresenta como específico do gênero feminino é o fato de que sua contribuição para a produção da existência é a produção da própria vida humana como tal em contraponto as atividades e posições sociais atribuídas aos homens de ter um trabalho assalariado e participar na vida política $[\ldots] \cdot{ }^{37}$

As experiências reprodutivas e o cuidado para com os filhos são atividades relacionadas à produção e reprodução da existência humana e, portanto, de gênero feminino, sendo, além disso, desenvolvidas basicamente por mulheres. Durante séculos, seja no espaço da intimidade, ${ }^{38}$ seja no espaço da expressão pública, ${ }^{39}$ essa associação entre gênero feminino e vida reprodutiva foi naturalizada: a maternidade e o amor à criança pequena seria da natureza dos instintos nas mulheres.

Nesse mesmo artigo, Izquierdo apresenta uma rica e interessante sistematização dos usos do termo e do conceito de "gênero", ${ }^{40}$ os quais podem incorrer em abusos de diferentes tipos, pela imprecisão de suas abordagens, entre eles:

- não se usa nem o termo e nem o conceito estudos que adotam termos como "homem", "mulher", "macho", "fêmea", "masculino", "feminino" para caracterizar a ordem social que considera a masculinidade e a feminilidade como partes dos atributos sexuais, naturais e que condicionam 
as capacidades das pessoas para realizar qualquer atividade ou ocupar qualquer posição social. Por exemplo, "as mulheres têm instinto maternal, os homens instinto agressivo" (p. 25);

- usa-se o termo e não o conceito - estudos que substituem mecanicamente o termo "sexo" pelo termo "gênero", estratégia comum em pesquisas de natureza quantitativa (notadamente em quadros e tabelas, quando referem os informantes homens como gênero masculino e as mulheres como gênero feminino), mas também presente em estudos qualitativos quando focalizam as diferenças, sem compreendê-las como desigualdades.

Para além da complexidade que têm assumido os (ab)usos do conceito de "gênero" nas Ciências Humanas e Sociais, a distinção que coloca de um lado sexo-biologia e do outro gênero-cultura tem sido também questionada. A própria diferenciação sexual (macho e fêmea) tem sido colocada em suspeição, não sendo considerada como algo definitivo, a-histórico e determinado exclusivamente pelos conhecimentos e verdades oriundas das medidas e instrumentos produzidos pelas ciências da natureza. Como podemos observar em Barbieri,

Na espécie humana se distinguem vários níveis da diferença sexual: o sexo cromossômico, o sexo gonadal, o hormonal, o anatômico e o fisiológico. Porém, este conhecimento é muito recente na história humana, pelo que se pode supor que os sistemas de gêneros se têm constituído a partir da observação das diferenças anatômicas e fisiológicas para a qual não tem sido necessário o uso de microscópios

${ }^{41}$ BARBIERI, 1992, p. 114 , tradução nossa da nota de rodapé 6.

42 LAQUEUR, 2001. eletrônicos para se fazerem evidentes. ${ }^{41}$

Assim, também os usos do conceito de "sexo" têm sido alvo de questionamentos. O historiador Thomas Laqueur, em seu livro Inventando o sexo: corpo e gênero dos gregos a Freud, investigou inúmeros conceitos relacionados à construção das diferenças sexuais. ${ }^{42}$ Ele relata minuciosamente as observações que afirmavam, desde a filosofia grega, um modelo de sexo único. A mulher era o homem invertido. Os estudos de anatomia buscavam correspondências nos corpos. Como descreve Jurandir Freire Costa, a partir das idéias de Laqueur,

A noção de sexo estava subordinada à idéia da perfeição metafísica do corpo masculino. A hierarquia sexual ia da mulher ao homem. Sexo tinha como referente, exclusivamente, os órgãos reprodutores do homem. A natureza havia feito com que a mulher não tivesse o mesmo calor vital do homem, a fim de que 
${ }^{43}$ COSTA, 1995, p. 6.

${ }^{44}$ COSTA, 1995, p, 7.

${ }^{45}$ STOLCKE, 2006, p. 16-17. pudesse abrigar o esperma e os óvulos fecundados sem destruí-los. A frieza da mulher era necessária à reprodução. Se a mulher fosse tão quente quanto o homem, o embrião poderia ser dissolvido. ${ }^{43}$

Contudo, a partir do século XVIII, a caracterização do corpo não se fazia mais com o objetivo de buscar semelhanças, mas diferenças. Procuraram-se evidências de que o orgasmo feminino não é necessário à concepção, e esse argumento vai ser essencial ao modelo de sexos opostos incomensuráveis. Lacquer mostra como os dois modelos sexo único e sexos opostos - coexistem, sendo empregados conforme o contexto de disputas dos significados sociais.

Uma das explicações plausíveis fornecidas por Costa para a atual oposição binária entre os corpos masculino e feminino é que essa diferenciação, embora aparentemente natural, teria um fundamento político, localizado nos interesses da sociedade burguesa:

[...] os ideais igualitários da revolução democráticoburguesa tinham que justificar a desigualdade entre homens e mulheres, com fundamento numa desigualdade natural [...]. Para que as mulheres, assim como os negros e os povos colonizados, não pudessem ter os mesmos direitos de cidadãos homens, brancos e metropolitanos, foi necessário começar a inventar algo que, na natureza, justificasse racionalmente as desigualdades exigidas pela política e pela economia da ordem burguesa dominante. ${ }^{44}$

Verena Stolcke oferece uma contribuição valiosa para discutir as relações sociais generificadas, a partir da análise histórica da constituição da sociedade colonial iberoamericana no artigo "O enigma das interseções: classe, 'raça', sexo, sexualidade - a formação dos impérios transatlânticos do século XVI ao XIX", em cuja argumentação, defende a autora,

A experiência colonial ibérica permite assim transcender as justaposições e aliterações convencionais dos critérios de identificação de classe, raça e gênero. $O$ gênero não trata de mulheres como tais. Refere-se aos conceitos que prevalecem em uma sociedade sobre o que são as mulheres em relação aos homens enquanto seres humanos sexualmente identificados [...] Torna-se exemplo também das conseqüências que a moralidade sexual e os estereótipos de gênero prevalentes tiveram para todas as esferas da vida das mulheres. ${ }^{45}$

Em síntese, é importante reconhecer que a leitura sobre o sistema sexo/gênero aqui adotada não reifica a dicotomia natureza-cultura, mas busca compreender os usos 
46 SCOTT, 1995.

${ }^{47}$ BARBIERI, 1992, p. 114 , tradução nossa.

${ }^{48}$ SARTI, 2004

${ }^{49}$ SARTI, 2004, p. 47.

50 STRATHERN, 1987. e efeitos que práticas sociais, inclusive as científicas, produzem a partir do exercício constante de oposição ou de busca de similitude entre os dois sexos. Apostamos, ao contrário, na complexa teia que define as relações de gênero, que nos aponta mais para a diversidade do que para a diferença, como resposta à dicotomia e à desigualdade.

Partimos, assim, para o segundo componente do marco conceitual aqui proposto: a dimensão relacional que o conceito de "gênero" trouxe para nosso vocabulário analítico. ${ }^{46} \mathrm{O}$ gênero não pode ser pensado como entidade em si, mas como construções interdependentes. Nessa perspectiva, Barbieri defende que

não se pode apenas estudar as mulheres, pois o objeto dos estudos de gênero é mais amplo, e, sendo assim, faz-se necessária uma análise em todos os níveis, âmbitos e tempos, das relações mulher-homem, mulher-mulher, homem-homem para se alcançarem maiores resultados. ${ }^{47}$

Porém, é necessário considerar que relacional não implica complementaridade, mas assimetria de poder. É preciso, portanto, submeter o conceito de "gênero" a uma leitura feminista. Ou seja, deve-se adotar a perspectiva de gênero, buscando compreender como diferenças se constituem em desigualdades, indo além dos sexos como determinantes biológicos e da 'di-visão' sexual do mundo. Com efeito, como defende Sarti, em artigo anteriormente referido, ${ }^{48}$ é preciso a adoção de uma perspectiva que rompa com a visão feminista dicotômica que adota a noção de dominação, desconsiderando o jogo relacional de poder entre o eu e o outro:

Pressupondo a dominação, o outro é necessariamente o dominador, portanto o conhecimento sobre a mulher exclui o outro [o homem]. A prática antropológica, ao contrário, volta-se para o reconhecimento do outro, preservando a distância entre eu e o outro, não havendo qualquer oposição predeterminada. 0 problema é, então, como estabelecer os termos da comunicação possível, tendo em vista que se pretende a relação com o outro. ${ }^{49}$

A partir dessa provocação, a autora destaca, fazendo referência a Marilyn Strathern, ${ }^{50}$ que "o Outro" que está sob ataque não é necessariamente o "não-eu". Ao contrário, é a parte do eu que é corporificada na tradição da qual somos, homens e mulheres, herdeiros.

A análise sobre essa tradição nos remete, assim, à necessidade de reflexões sobre a construção de masculinidades e feminilidades que vão além da vitimização de 
${ }^{51}$ MEDRADO, 1996.

${ }^{52}$ GOMÁRIZ, 1992.

${ }_{53}$ Ver Pedro OLIVEIRA, 2000; Rosely COSTA, 2002; e FIGUEROA-PEREA, 2003.

${ }^{54}$ Ver Fúlvia ROSEMBERG, 1997; e STOLCKE, 1992 e 2006.

55 ROSEMBERG, 1997, $2001 \mathrm{e}$ 2002. alguns (mulheres) e da culpabilização de outros (homens). Afinal, reconhecer a dimensão relacional do gênero possibilita desconstruir principalmente os argumentos culpabilizantes sobre os homens que demarcam o discurso de parte do movimento feminista e que ainda se faz presente, direta ou indiretamente, nas produções acadêmicas contemporâneas. Como destaca Medrado, ao invés de procurar os culpados, é necessário identificar como se institucionalizam e como se atualizam as relações de gênero, possibilitando efetivamente transformações no âmbito das relações sociais "generificadas", ou seja, orientadas pelas desigualdades de gênero. ${ }^{51}$

Isso não implica processo de desresponsabilização individual, mas reconhecer que as análises que agregam a dimensão relacional do conceito de "gênero" permitem compreender ou interpretar uma dinâmica social que hierarquiza as relações entre o masculino e o feminino e não apenas entre homens e mulheres, mas nos homens e nas mulheres.

É, então, quando as teorias feministas forjam o conceito de "gênero" nessa dimensão relacional que os estudos sobre homens e masculinidades como objeto de análises ganham maior ênfase, ${ }^{52}$ porém não isenta de críticas, as quais iremos apresentar no próximo tópico. ${ }^{53}$

Já está claro que o exercício analítico proposto neste estudo busca (embora reconheça que nem sempre é fácil nadar contra a maré!) fugir das lógicas binárias e polarizadas das relações de gênero entre masculino e feminino ao incluir um olhar para as intersecções com outros marcadores sociais. ${ }^{54}$ Faz-se necessário considerar, por exemplo, as categorias de "raça/etnia", "idade", "sexualidade" e "condição sócio-econômica".

Fúlvia Rosemberg, ${ }^{55}$ em suas pesquisas sobre educação infantil, trabalha as dimensões "gênero", "raça" e "idade" com vistas a construir um modelo teórico que não associe essas três dimensões da sociedade como adjetivas ou associativas. Ela tem usado o conceito de "heterocronia", ou de "não-sincronia" dessas dimensões, além de concebêlas como relações de hierarquia, de subordinação. Gênero, raça e idade, do ponto de vista da história social, e do ponto de vista do ciclo de vida, da trajetória pessoal, não atuam no mesmo momento e na mesma direção na vida das pessoas, sendo fundamental complexificar esse olhar.

Essa complexidade é exigida ao adotarmos a dimensão relacional de gênero, evitando-se, assim, uma leitura marcada pela dicotomia e permitindo inclusive a emergência de outros objetos de pesquisa, a partir da abordagem de gênero, dentro de uma perspectiva feminista, que tem o poder como dimensão central de análise. 
${ }^{56}$ SCOTT, 1995, p. 86.

57 SCOT, 1995, p. 88.

${ }^{58}$ SCOTT, 1995, p .86.

${ }^{59}$ FOUCAULT, 1982, 1990 e 1996.
Chegamos, assim, ao terceiro componente de nosso marco conceitual: as relações de poder.

Joan Scott propõe uma definição de gênero a partir da conexão integral entre duas proposições: "(1) o gênero é um elemento constitutivo de relações sociais baseadas nas diferenças percebidas entre os sexos e (2) o gênero é uma forma primária de dar significado às relações de poder". ${ }^{56}$ Ou, mais precisamente, "o gênero é um campo primeiro no interior do qual, ou por meio do qual, o poder é articulado". ${ }^{57}$ Ela propõe que precisamos adotar a perspectiva foucaultiana de poder, entendido como jogos desiguais inscritos em práticas discursivas que constituem "campos de forças sociais". ${ }^{58}$

Em sua obra, Michel Foucault busca dar conta dos inúmeros mecanismos e efeitos de poder que atravessam toda a sociedade. ${ }^{59}$ Não é possível trazer aqui a contribuição substancial desse autor ao debate sobre poder, mas buscaremos, em algumas de suas produções, argumentos e conceitos que nos parecem úteis para configuração das relações de poder, que junto com os demais elementos constituem o marco conceitual ora proposto.

Nas contribuições desse autor, consideramos relevante o enfoque dado por ele aos dispositivos de exercício do poder, ou seja, a tecnologia por meio da qual se obtém a sujeição, mecanismos de poder que controlam o corpo minuciosamente (gestos, atitudes, discursos), redes de dispositivos de poder à qual não se escapa. Esses dispositivos são

[...] um conjunto decididamente heterogêneo que engloba discursos, instituições, organizações arquitetônicas, decisões regulamentares, leis, medidas administrativas, enunciados científicos, proposições filosóficas, morais, filantrópicas. Em suma, o dito e o não-dito são os elementos do dispositivo. O dispositivo é a rede que se pode estabelecer entre estes elementos. ${ }^{60}$

É o exercício de micropoderes em redes mais ou menos hierárquicas, onde cada um é centro de transmissão de poder. Na sua concepção, não existe poder fora de seu exercício, não se possui poder, exerce-se poder. ${ }^{61}$ Assim, como destaca Medrado, raras vezes Foucault emprega o termo "poder" de modo isolado, como um substantivo simples. ${ }^{62}$

Quando se fala em poder, em geral as pessoas imediatamente associam a idéias já estabelecidas: pensam em estruturas de poder político, em governos, em classes dominantes, em nações "imperialistas", em chefes em relação aos empregados, em senhores e escravos. Mas não é apenas a esse tipo de substantivação ou materialidade dos jogos de poder a que se refere Foucault. Relações de 
${ }^{63}$ MEDRADO, 2002.

${ }^{64}$ VALE DE ALMEIDA, 1996.

65 VALE DE ALMEIDA, 1996; MEDRADO, 1997; e FIGUEROAPEREA, 2005.

${ }^{66}$ SCOTT, 1995, p. 86. poder são quaisquer relações humanas - institucionais, econômicas, amorosas, interações verbais. São relações tão diversas quanto possíveis, que podemos encontrar em diferentes situações e contextos, sob diferentes e (mais ou menos) complexas formas.

Na perspectiva foucaltiana, liberdade e poder não são elementos mutuamente excludentes, na medida em que as relações de poder só se processam quando existe algum grau de liberdade e resistência entre as pessoas envolvidas. A idéia de que onde há relações de poder não há liberdade é, para ele, completamente falsa. Se existem relações de poder é exatamente porque existem possibilidades de liberdade por todas as partes. Ou seja, a resistência é um elemento constitutivo da relação de poder. Nas relações de poder existem necessariamente possibilidades de resistência, na medida em que, se não existe possibilidade de resistência - fuga, reação violenta, subterfúgios, estratégias para inverter a situação -, não existem relações de poder.

Vale destacar que existem diferenças significativas entre relações de poder e estados de dominação. Um estado de dominação é o total bloqueio de um campo de relações de poder, tornando essas relações imóveis e fixas, dessimétricas, com limitada margem de liberdade, impedindo qualquer reversibilidade. Como destaca Medrado, é importante atentar que, quando fala de poder, Foucault usa propositalmente o termo "relações" ao contrário de quando trata de dominação, em que ele emprega o termo "estados", marcando exatamente o potencial de mobilidade do primeiro. ${ }^{63}$

Portanto, o debate sobre as relações de poder que inscrevem masculinidades e feminilidades em nossa cultura é fundamental. Como destaca Miguel Vale de Almeida, masculinidade e feminilidade são metáforas de poder e de capacidade de ação que orientam valores e práticas sociais de homens e mulheres. ${ }^{64}$

Esse núcleo é compartilhado, a despeito de diferenças de nuance, pela grande parte dos/as autores/as contemporâneos/as que vem estudando os homens e as masculinidades. ${ }^{65}$ Mas o aporte instigante de Scott é sua explicação dos componentes embutidos na primeira parte de sua conceituação, na qual gênero é definido como "um elemento constitutivo das relações sociais baseadas nas diferenças percebidas, o gênero implica quatro elementos inter-relacionados". ${ }^{66}$ A inter-relação entre os quatro elementos (apresentados adiante) significa, para essa autora, que nenhum dentre eles pode operar sem os outros, e que não operam simultaneamente, como se um fosse reflexo do outro. Nesse sentido, a autora não estabelece 
${ }^{67}$ SCOIT, 1995, p. 86.

${ }^{68}$ SCOTT, 1995, p. 86.

${ }^{69}$ SCOTT, 1995, p. 86.

70 SCOT, 1995, p. 88.

71 IZQUIERDO, 1994.

72 SCOT, 1995, p. 88. hierarquias ou anterioridades entre elementos determinantes e determinados.

O primeiro elemento destacado por ela são "[...] os símbolos culturalmente disponíveis que evocam representações simbólicas (e com frequência contraditórias - Eva e Maria como símbolos da mulher, por exemplo, na tradição cristã ocidental - mas também mitos de luz e escuridão, purificação e poluição, inocência e corrupção". ${ }^{67}$

Em segundo lugar, Scott destaca os conceitos normativos "que expressam interpretações dos significados dos símbolos, que tentam limitar e conter suas possibilidades metafóricas". ${ }^{68}$ São os conceitos prescritivos, que afirmam o masculino e o feminino de forma binária inequívoca por meio de doutrinas religiosas, educativas, científicas, políticas ou jurídicas. Esses campos doutrinários, prescritivos, são algumas vezes abertamente contestados, porém "a história posterior é escrita como se essas posições normativas fossem o produto do consenso social e não do conflito". 69 Isso traz, evidentemente, uma conotação de fixidez à prescrição.

O terceiro elemento proposto por Scott é a identidade subjetiva, a atualização concreta, por homens e mulheres, de suas identidades de gênero: "[...] os homens e as mulheres reais não cumprem sempre, nem cumprem literalmente, os termos das prescrições de suas sociedades ou de nossas categorias analíticas". ${ }^{70}$ Scott destaca, como o fizera também Izquierdo, ${ }^{71}$ a centralidade da reprodução: "[...] o sociólogo francês Pierre Bourdieu tem escrito sobre como a 'di-visão do mundo', baseada em referência às 'diferenças biológicas', e, notadamente, àquelas que se referem à divisão do trabalho de procriação e de reprodução, operam como a mais fundada das ilusões coletivas". ${ }^{72}$

Assim, o suposto destino biológico da mulher à maternidade tem sido construído por meio de símbolos, de prescrições religiosas, jurídicas, educacionais, das organizações sociais e das identidades subjetivas. Em contrapartida, o masculino, ao ser associado 'à produção e administração da riqueza', é afastado do 'reino' da reprodução a não ser pelo sêmen fecundante. Intersubjetividades de mulheres e de homens escapam às prescrições, bem como sua organização social em movimentos políticos.

O quarto aspecto das relações de gênero destacado por Scott constitui também nosso quarto e último elemento do marco conceitual aqui proposto: é a tradução do modelo binário e fixo de homem e de mulher no nível da política, das instituições e organizações sociais. Segundo a autora, o gênero constrói-se não de forma binária, mas na multiplicidade de instituições, que envolve não apenas a família ou as relações de parentesco: "ele é construído igualmente na 
${ }^{73}$ SCOTT, 1995, p. 87.

\begin{abstract}
${ }^{74}$ Para a construção dessa matriz, tomamos por base especialmente as produções de VALE DE ALMEIDA, 1995 e 1996; LYRA, 1997; MEDRADO, 1997; FIGUEROAPEREA, 1998 e 2003; ARILHA, UNBEHAUM E MEDRADO, 1998; ARILHA, 1999 e 2005; e Benedito MEDRADO, Jorge LYRA, Karla GALVÃO e Pedro NASCIMENTO, 2000.
\end{abstract}

${ }^{75}$ Sobre esse aspecto, recomendamos a leitura de BADINTER, 1993; CONNELL, 1995a; Richard PARKER e John GAGNON, 1995; Carole VANCE, 1995; MEDRADO, 1997; Carlos CÁCERES, 2000; e Daniel WELZER-LANG, 2001.

76 PARRINI, 2006. economia e na organização política, que, pelo menos em nossa sociedade, operam atualmente de maneira amplamente independente do parentesco". ${ }^{73}$ Assim, a reflexão que queremos propor aqui tem o desafio de romper com tais modelos binários, propondo uma leitura sobre gênero não a partir de sua dimensão binária, mas sim relacional.

\section{Homens, masculinidades e poder: outros olhares feministas}

Na literatura analisada com vistas a formular o marco referencial acima, recortamos os estudos que adotam uma concepção feminista de gênero: construção social que engendra e legitima o poder masculino. ${ }^{74} \mathrm{O}$ ponto de partida de nossas reflexões sobre homens e masculinidades, baseadas nesse marco conceitual, é que não existe uma única masculinidade e que tampouco é possível falar em formas binárias que supõem a 'di-visão' entre formas hegemônicas e subordinadas. Tais formas dicotômicas baseiam-se nas posições de poder social dos homens, mas são assumidas de modo complexo por homens particulares, que também desenvolvem relações diversas com outras masculinidades.

Destacamos o emprego das conceituações feministas e de gênero, com vistas a explicitar em que lugar situamos nossa argumentação e em que fundamentos se baseia a origem de nossas reflexões, além de incorporar as críticas que se fazem ao campo de estudos sobre masculinidade.

Essa busca de clareza nos argumentos não é fruto apenas de um exercício retórico, mas principalmente por acreditarmos e defendermos que as discussões sobre os homens e as masculinidades, de forma crítica, são resultados dos desafios e avanços dos debates científicos e políticos originalmente produzidos pelo movimento feminista e pelo movimento em defesa da diversidade sexual. ${ }^{75}$ Quando se pretende (re)fazer perguntas ao campo da produção de conhecimento, ainda fortemente sexista e androcêntrico, tanto como (re)significar relações sociais de poder e desconstruir o machismo institucionalizado, que se expressa cotidianamente em nossa sociedade, é necessário adotar essa matriz analítica e de compreensão ético-conceitual.

É nesse sentido que as questões, aparentemente óbvias, que Rodrigo Parrini, antropólogo chileno, apresenta em seu texto intitulado ¿Existe la masculinidad? Sobre un dispositivo de saber/poder ${ }^{76}$ são muito interessantes, pois questionam os princípios que norteiam o próprio campo. $\mathrm{O}$ elemento principal dessas considerações propostas pelo autor é trazer à baila uma forte crítica aos estudos autônomos 
77 PARRINI, 2006, p. 1.

${ }^{78}$ PARRINI, 2006.

79 FIGUEROA-PEREA, 2003.

${ }^{80}$ OLIVEIRA, 2000.

${ }^{81}$ Rosely COSTA, 2002.

${ }^{82}$ FIGUEROA-PEREA, 2003. O texto foi publicado no livro Homens: tempos, práticas e vozes (Benedito MEDRADO, Mônica FRANCH, Jorge LYRA e Maíra BRITO, 2004).

${ }^{83}$ Vale salientar que não assumimos aqui gênero a partir da relação entre dois. A dimensão de poder entre gêneros sobre a qual fala FIGUEROA-PEREA, 2003, ultrapassa uma leitura binária. ${ }^{84}$ FIGUEROA, 2003-PEREA. da masculinidade. No seu entender, e de acordo com o que aqui defendemos, esse campo de estudos autônomos sobre masculinidades é "um espaço atrasado e em muitos sentidos reacionário quando comparados aos estudos de gênero, feminismo e teorias queer, principalmente em função da definição do seu objeto de estudo", ${ }^{77}$ e também com vago aprofundamento teórico e com pouca solidez na revisão histórica.

Segundo esse autor, considerar a masculinidade e os homens objetos específicos dos estudos da masculinidade acarreta conseqüências teóricas e políticas sérias. Politicamente, reforça o binarismo que tem sido fortemente criticado atualmente pelas teorias feministas e, mais recentemente, pelas teorias queer. Teoricamente, ao trabalhar a partir de uma divisão ingênua entre masculinidade e feminilidade, não incorpora as severas críticas das políticas de identidade, a complexificação do estudo da subjetividade e a centralidade das reflexões sobre as relações de poder que configuram os objetos que se relacionam diretamente a sexo, a gênero ou a ambos. ${ }^{78}$

Juan Guillermo Figueroa-Perea, ${ }^{79}$ uma das principais referências no debate sobre os homens no campo dos direitos reprodutivos na América Latina, tem desenvolvido na última década uma profunda sistematização e reflexão crítica sobre esse tema. Outros autores brasileiros, entre eles Pedro Paulo Oliveira ${ }^{80}$ e Rosely Costa, ${ }^{81}$ também têm arrolado críticas sobre os estudos da masculinidade.

Na abertura do II Seminário Internacional "Homens, Sexualidade e Reprodução", organizado pelo Instituto PAPAI, Núcleo Fages, Grupo Pegapacapá e NEPO-UNICAMP, em Recife (em 2003), Figueroa-Perea fez uma conferência intitulada La representación social de los varones en estudios sobre masculinidad y reproducción: "un muestrario de reflexiones". ${ }^{82}$ Nessa conferência, ele explicita suas referências analíticas e compartilha quais são as dimensões que ele sugere trabalhar para repensar criticamente o que se nomeia "estudos sobre masculinidade", que o próprio autor prefere chamar de "Estudos sobre os homens e as relações de poder entre os gêneros". ${ }^{83}$

A rica contribuição de Figueroa-Perea, ${ }^{84}$ descrita mais detalhadamente a seguir, auxilia a compreender como os discursos das políticas produzem concepções de masculinidades e de homens e definem posições a serem ocupadas pelos sujeitos. Nesse sentido, investigar sobre masculinidades significa não apenas apreender e analisar os signos e significados culturais disponíveis sobre o masculino, mas também discutir preconceitos e estereótipos e repensar a possibilidade de construir outras versões e sentidos. Situa-se, portanto, nos usos e efeitos que orientam 
${ }^{85}$ Maria Filomena GREGORI, 2003.

os jogos de discursos e práticas, ou mais precisamente práticas discursivas, que tendem a transformar diversidade em desigualdade.

Por certo, ao longo da história, as mulheres têm sido alvo de injustiças sociais de ordens variadas e, por mais conquistas que tenham alcançado, ainda está distante poder-se falar sobre uma efetiva igualdade de gênero. Por outro lado, muitos homens em condições sociais (a)diversas também enfrentam, cotidianamente, a impossibilidade/ obrigação de responder ao modelo hegemônico de masculinidade.

Poder-se-ia ler a afirmativa acima como um posicionamento vitimário. Porém, a resistência em perceber as relações de poder como jogos, e não como estados, pode, por outro lado, inviabilizar a percepção de caminhos de transformação, mantendo conseqüentemente os lugares de mulher-vítima e homem-algoz como estáveis e imutáveis. ${ }^{85}$ A dominação dos homens sobre as mulheres e sobre o feminino não possui autoria única, mas uma constelação de autores, que inclui, além dos homens, a mídia, a educação, a religião, as mulheres e as próprias políticas públicas. Em outras palavras, partimos da perspectiva de que o poder coletivo dos homens não é construído apenas nas formas como os homens interiorizam, individualizam e o reforçam, mas também nas instituições sociais.

Na seqüência, sintetizamos alguns pontos que consideramos importantes para caracterizar esse campo de investigação em constante ebulição, também produtor de discursos, de modos de saber e de fazer e de sujeitos.

Refletindo sobre os estudos sobre homens e masculini-

${ }^{86}$ FIGUEROA-PEREA, 2003. dades no campo da Saúde e Direitos Sexuais e Reprodutivos, Figueroa-Perea propõe as seguintes questões: ${ }^{86}$

1. Que temas têm sido objeto de pesquisas?

2. Como se investigam os difere ntes temas?

3. Qual é o ponto de vista que se adota na formulação do conhecimento?

4. Que concepções de homem orientam estes estudos?

5. Quais são as sugestões de temas para futuras pesquisas?

6. Que novos discursos, novas palavras estão sendo inventadas pelo campo?

7. O que se quer com estes estudos sobre masculinidades?

8. Que categorias analíticas são usadas?

9. Há desconfianças do conhecimento produzido sobre os homens? 
${ }^{87}$ FIGUEROA-PEREA, 2003.

${ }^{88}$ Nelson MINELLO, 2002.

${ }^{89}$ Rosely COSTA, 2002.

${ }^{90}$ FIGUEROA-PEREA, 2003.
A partir da pergunta Que temas têm sido objeto de pesquisa no decorrer do tempo?, Figueroa-Perea ${ }^{87}$ identifica os temas que têm sido trabalhados exaustivamente e outros que surgiram apenas mais recentemente e, mesmo assim, com dificuldades. Problematiza, também, por que alguns temas não são trabalhados. Segundo o autor, há nesse campo um maior foco nos estudos sobre sexualidade, saúde e violência em detrimento de discussões sobre a reprodução, gerando uma produção ainda incipente do ponto de vista do aprofundamente teórico-metodológico e epistemológico. Uma possível justificativa trazida por esse autor é o interesse em fazer intervenções em situações diversas, contando com recursos disponíveis, mas que, em busca de resultados rápidos, não há um acúmulo e aprofundamento das compreensões sobre os fenômenos. ${ }^{88}$ Essa questão dos recursos também é apontada por Rosely Costa $^{89}$ quando afirma que os estudos sobre masculinidades emergiram a partir do incentivo de agências financiadoras nacionais e internacionais, que, devido às preocupações com o controle de natalidade nos países em desenvolvimento, visavam a um maior conhecimento dos homens.

Ao refletir sobre Como se investigam os diferentes temas?, Figueroa-Perea ${ }^{90}$ ressalta que é necessário não apenas atentar para os temas emergentes no campo, mas que devemos observar especialmente como têm sido feitas essas investigações. Em suas análises, ele destaca que algumas pesquisas sobre masculinidades tomam os homens como únicos informantes, sem fazer nenhuma alusão aos argumentos, depoimentos ou narrativas de mulheres. Algumas até fazem referências a homens e mulheres, mas suas análises muitas vezes se baseiam, única e exclusivamente, em diferenças comportamentais (genéticas, hormonais, etc.), tomadas a partir de uma abordagem tipificadora. Em outros estudos, considera-se que as pesquisas que têm mulheres como informantes já contemplam muitas informações sobre os homens e que, portanto, essas informações podem ser analisadas sem necessariamente gerar a necessidade de incluir análises a partir de depoimentos dos homens.

Embora o autor, propositalmente, não cite diretamente muitos autores ou obras, preferindo falar em tendências e movimentos, é possível perceber claramente essa dinâmica, que não parece constituir necessariamente grupos em disputa, mas procedimentos comuns nas obras inclusive de mesmos autores ou autoras. Observam-se nesses exemplos, trazidos por Figueroa-Perea, ${ }^{91}$ alguns problemas na produção de conhecimento desse campo. Em linhas gerais, percebe-se a presença de sexismos, tão criticados pelo feminismo, expressos a partir da postura binária e da não- 
92 FIGUEROA-PEREA, 2003.

\begin{abstract}
${ }^{93}$ Essa característica de considerar os homens como "vítimas" também foi discutida e criticada por Pedro OLIVEIRA, 2000, e Rosely COSTA, 2002.
\end{abstract}

${ }^{94}$ FIGUEROA-PEREA, 2003.

95 FIGUEROA-PEREA, 2003.

${ }^{96}$ FIGUEROA-PEREA, 2003.

97 FIGUEROA-PEREA, 2003. adoção da perspectiva relacional; naturalizam-se as diferenças sexuais, a partir da mera tipificação de comportamentos tidos como masculinos e femininos; apresentam-se tensões entre visibilidade/invisibilidade dos sujeitos e revelam-se análises fundamentadas em informações indiretas.

Continuando esse processo de caracterização e análise do campo, além de mapear que procedimentos metodológicos têm sido empregados nos estudos de masculinidades, Figueroa-Perea ${ }^{92}$ chama a atenção também para entendermos Quais as concepções de homens orientam estes estudos?. Ele organizou essas concepções em pelo menos cinco perspectivas: 1) "satanização dos homens"; 2) "homens como vítimas";93 3) "auto-flagelação"; 4) "desigualdades de gênero patriarcais"; e 5) "uma leitura que contextualiza as normas". Mais adiante, traremos um maior detalhamento formulado pelo autor.

Outra importante pergunta oriunda do debate sobre o fazer científico apresentado por Figueroa-Perea ${ }^{94}$ refere-se a como devemos abordar o tema das masculinidades (e outros objetos de pesquisas em gênero): de forma indutiva ou dedutiva? Ou seja, qual é o ponto de vista que se adota na formulação do conhecimento? Parte-se do que os homens fazem e buscam-se certas diferenças (e semelhanças) com as mulheres (e com os próprios homens) e tenta-se entender a origem e o significado dessas diferenças e semelhanças ou, a partir de uma determinada concepção teórica de masculinidade, vai-se a campo buscando comprová-la dedutivamente na prática? $\mathrm{Na}$ compreensão de Figueroa-Perea, ${ }^{95}$ a qual compartilhamos, é fundamental explicitar de que lugar e como se interpreta a masculinidade, se uma condição, uma essência, uma característica ou um privilégio?

Reconhecendo que exercício da análise da produção teórica sobre um tema é fundamental para identificar equívocos, revisar caminhos e também perceber os avanços, Figueroa-Perea ${ }^{96}$ questiona essa literatura a partir da pergunta: Quais são as sugestões de temas para futuras pesquisas? Uma das características que se apontam em vários estudos é a dimensão do poder em suas diferentes modalidades, não apenas com vistas a identificá-lo, o que na sua acepção seria uma leitura eminentente dedutiva, mas questionar como os indivíduos concretos processam o exercício do poder, como o reproduzem e também como o transgridem, ou seja, questionam-no e transformam-no em relações mais democráticas.

Figueroa-Perea ${ }^{97}$ propõe, então, que se criem, se inventem palavras para que novas/outras realidades passem 
${ }_{98}^{8}$ Sócrates NOLASCO, 1993, 1995 e 2001; e Luiz CUSCHINIR, 2002, por exemplo.

99 OLIVEIRA, 2000.

100 FIGUEROA-PEREA, 2003.

101 FIGUEROA-PEREA, 2003. a existir. Com esse espírito, ele segue sua leitura panorâmica das produções sobre masculinidades questionando: Que novos discursos, novas palavras estão sendo inventadas pelo campo? Aqui ele faz referência ao uso recorrente em pesquisas do conceito de "masculinidade hegemônica", que tem como antítese as masculinidades subordinadas ou subalternas. O uso da expressão "masculinidade hegemônica" tornou-se quase lugar-comum nas pesquisas sobre homens e masculinidades, entretanto Figueroa-Perea questiona o caráter a-histórico e universal dessa construção.

De fato, ao se empregar a expressão "masculinidade hegemônica", nessa leitura acaba-se materializando (ou substantivando) um jogo ou processo de poder, produzindo leituras binárias, sem reconhecer a dimensão relacional de gênero.

Nesse contexto, outras expressões que emergem no âmbito dos estudos sobre masculinidades são postas em xeque. Por exemplo, na literatura, especialmente aquela produzida no contexto da psicologia clínica, que toma por base informações obtidas com homens atendidos em consultórios privados, ${ }^{98}$ utiliza-se comumente a expressão "crise da masculinidade", mas se observa que poucos homens se reconheçam nessa situação. Coloca-se, assim, a pergunta feita por Pedro Paulo Oliveira: que homens estão em crise? ${ }^{99}$ E acrescentamos: seria a crise da masculinidade ou tão-somente alguns homens em crise?

O que se quer com estes estudos sobre masculinidades? é outra intrigante pergunta que Figueroa-Perea ${ }^{100} \mathrm{faz} \mathrm{a}$ esse campo de estudos e pesquisas. Tendo em vista que as perguntas de pesquisas orientam as perspectivas analíticas no desenvolvimento de estudos sobre a população masculina, o autor destaca que as pesquisas nesse campo vão desde propostas unilaterais de intervenção e modificação de atitudes até processos mais sistemáticos, que buscam historiar comportamentos e mapear múltiplas causas de suas modalidades, adotando uma perspectiva mais construcionista.

Esse segundo movimento pode ser levado a cabo tendo como ponto de partida a perspectiva de gênero, mas também pode adotar uma leitura parcial, seja a partir de um olhar voltado aos homens, seja exclusivamente às mulheres. De acordo com a análise desse autor, essa decisão passa pela delimitação de como se entende o próprio campo: 1) estudos sobre masculinidade; 2) estudos sobre homens e relações de gênero; ou 3) estudos de gênero sobre os homens. ${ }^{101}$

Para dar conta de analisar o desigual exercício de poder entre homens e mulheres, assim como a dupla moralidade a partir da qual se nomeiam e se produzem as 
102 FIGUEROA-PEREA, 2003.

${ }^{103}$ FIGUEROA-PEREA, 2003.

${ }^{104}$ ARILHA, 2005, p. 13.

${ }^{105}$ ARILHA, 2005. práticas de uns e de outras, precisamos perguntar que categorias analíticas são usadas? Esta é, assim, mais uma pergunta de Figueroa-Perea: ${ }^{102}$ que tipo de categoria é adotado na construção do objeto de estudo? O autor identifica quatro categorias - privilégios, necessidades, direitos e "malestares" - analisando-as a partir de suas diversas concepções, usos e críticas.

A constatação dos privilégios dos homens numa sociedade orientada pela ordem de gênero tem, segundo Figueroa-Perea, ${ }^{103}$ gerado importantes contribuições analíticas. Porém, tomada de forma acrítica, a categoria analítica privilégios impede o reconhecimento de que o exercício do poder pelos homens pode trazer efeitos negativos associados (ou desvantagens) como conseqüência.

Outra categoria aponta para as necessidades dos homens, baseando-se não necessariamente em demandas, mas em análises de condições de produção e vetores de (im)possibilidades trazidos pela 'di-visão' sexual do mundo. A esse respeito, Margareth Arilha, em sua tese de doutorado, questiona "por que não se constrói socialmente uma real escuta para as vulnerabilidades e necessidades dos homens, quando se fala de gênero?" E vai além: "O que é que 'gênero' está tematizando, quando fala das mulheres, e o que está tematizando quando fala dos homens?". ${ }^{104}$

Para além das necessidades, Figueroa-Perea traz direitos como outra categoria analítica que vem se legitimando, embora de forma ainda muito tímida. Direito pode ser entendido como condição humana, mas é preciso incluir nessa análise as condições de diferenças e desigualdades de gênero, para tornar mais complexo o seu entendimento. Na sociedade em que vivemos, direito pode ser entendido como algo inerente à condição masculina: os homens já são os sujeitos dos direitos e, portanto, falar nos homens seria invariavelmente falar em "posição de direito". Só a partir de uma análise crítica dessa noção genérica é possível qualificar seu uso com capacidade de transformação.

Arilha $^{105}$ ressalta iniciativas que, na última década, começaram a ganhar visibilidade e que apontam para campos de direito (especialmente o campo dos direitos reprodutivos) em que os homens (ou, pelo menos, uma parte deles) parecem não ocupar posições definitivas de direito. Porém, como alerta a autora, tem-se observado que o processo de inserção dos homens no debate sobre direitos reprodutivos tem sido feito de maneira ainda muito tímida; incipiente quando comparável ao que ocorreu com as mulheres, há pelo menos três décadas, no campo da sexualidade, reprodução, saúde sexual e reprodutiva e dos direitos das mulheres de forma mais ampla. 
106 FIGUEROA-PEREA, 2003, p. 20.

107 ARILHA, 2005, p. 14.

108 SCOTT, 1995.

${ }^{109}$ ARILHA, 2005, p. 14.
Figueroa-Perea reconhece que há "uma confusão entre direito e privilégio na medida em que se defende que se as mulheres tivessem os mesmos privilégios dos homens, se avançaria na busca pela igualdade ou ao menos se diminuiria a desigualdade". ${ }^{106}$ Todavia, segundo esse autor, esquece-se que muitos privilégios de gênero foram legitimados privando-se os direitos as mulheres, sendo necessário, a seu ver, democratizar os espaços de negociação mais do que buscar se igualar em privilégios.

De todo modo, como contraponto do direito, a expressão mais recorrente no campo da saúde reprodutiva, especialmente (mas não exclusivamente) nos (e a partir dos) documentos resultantes de conferências internacionais, quando se faz referência aos homens é responsabilidade, conceito especialmente trabalhado por Arilha em sua dissertação de mestrado, posteriormente analisado em sua tese, como no trecho a seguir:

\begin{abstract}
O eixo central do trabalho desenvolvido naquele momento [referindo-se à dissertação de mestrado] foi justamente uma crítica à noção de responsabilidade usada pelo texto da Conferência do Cairo, mostrando sua essência normativa, operando com uma visão cristalizada [...], contribuindo para sedimentar o estereótipo de que homens em geral [...] são irresponsáveis, devendo ser capturados por políticas especiais e educados para se tornarem 'responsáveis'. Se, por um lado, o trabalho era inovador e ousado na medida em que apontava para uma visão crítica da abordagem do masculino na Conferência, não foi possível, naquele momento, seguir adiante e aprofundar um eixo que parece promissor [...]. ${ }^{107}$
\end{abstract}

Baseada, então, em Joan Scott, ${ }^{108}$ Arilha ratifica que, em sua perspectiva, gênero é uma das primeiras maneiras de dar significado às relações de poder, ou que gênero é um primeiro campo por meio do qual o poder é articulado. Para Arilha, não se tem dado atenção especial a essa segunda parte da definição de Scott. Para ela, se gênero é também uma forma de estar no mundo, "como conceito orientador de análises, seria necessário investigar melhor suas possibilidades de problematizar o mal-estar masculino". ${ }^{109}$

Nessa mesma direção, Figueroa-Perea introduz sua última categoria, o "mal-estar" (ou, como o autor prefere, no plural: "malestares", em castelhano). Para esse autor, é preciso ter cuidado para não cairmos numa perspectiva maniqueísta a partir de um olhar unidirecional. É fundamental complexificar nossas análises, investigando em que medida os sujeitos considerados "vitimizadores" (agressores, detentores do poder) lidam com as situações nas quais eles 
${ }^{110}$ FIGUEROA-PEREA, 2003, p. 20.

111 FIGUEROA-PEREA, 2003.

112 Tom DIGBY, 1998, é citado por FIGUEROA-PEREA, 2003, como obra que adota essa perspectiva. exercem o poder, ou lhes é permitido ou promovido esse exercício e, mais além, se a conscientização desses homens, ou sua responsabilização sobre esse processo, é capaz de ressignificar seu posicionamento nas relações de poder.

A última pergunta apresentada por Figueroa-Perea em seu exercício de revisão panorâmica (por el momento, como ele mesmo chamou atenção) refere-se às dúvidas e incertezas que existem no campo de estudos sobre os homens. Há desconfianças do conhecimento produzido sobre os homens? Como esse campo de estudos, de modo geral, tem se desenvolvido com vistas a discutir certezas e verdades que se atribuem à quase metade da população, colocar em suspeição os próprios cânones até então existentes leva a uma postura, a princípio, de negação e de ressalva.

[...] histórias pessoais e sociais definem e condicionam expectativas, pré-conceitos e pressupostos carregados de valor que nem sempre se está atento sobre o que fazer, inclusive há fatos que resistem a isto levando a que se duvide da informação obtida com a população de estudo, em particular quando esta não coincide com os pressupostos e os marcos interpretativos de que se baseia [...]. ${ }^{110}$

A origem dessas desconfianças pode ser atribuída às cinco concepções sobre homens, anteriormente mencionadas (e agora mais bem exploxadas), que Figueroa-Perea ${ }^{111}$ condensou a partir da sistematização da análise da literatura latino-americana referente à temática: 1) satanização dos homens; 2) vitimização; 3) "autoflagelação"; 4) leitura patriarcal; e 5) leitura contextualizada de normas. O autor chama a atenção para uma postura maniqueísta nas três primeiras vertentes em virtude do pressuposto de uma busca em definir e encontrar quem são "as boas e os maus", mantendo polaridades que pouco contribuem ou avançam na compreensão da complexidade das propostas teóricas e políticas das relações de gênero balizadas no feminismo.

A primeira, ele define como a que "sataniza os homens". Os homens são o motivo, origem e causa, responsáveis e executores das desigualdades de gênero; são vistos como vitimizadores. ${ }^{112}$ Uma outra vertente, oposta, é a que reconhece os "homens como vítimas", entendendo que eles também sofrem as conseqüências dos condicionantes de gênero e, portanto, não são totalmente responsáveis pelo que fazem, e sim resultado das influências de gênero. Em seguida, o autor nomeia o processo de "autoflagelação", no qual os homens se consideram culpados dos problemas enfrentados pelas mulheres pela sua própria condição de 
113 Entre essas obras, FIGUEROAPEREA, 2003, cita Maria Coleta OLIVEIRA, Elizabete BILAC e Malvina MUSZKAT, 2000.

114 FIGUEROA-PEREA, 2003, faz referência aqui ao trabalho de Michael FLOOD, 1997.

115 Nesse conjunto, FIGUEROAPEREA, 2003, identifica os trabaIhos de Juan Carlos HERNÁNDEZ, 1995; e Teresa VALDÉS e José OLAVARRÍA, 1998.

116 Aqui, FIGUEROA-PEREA, 2003, faz referência ao trabalho de PARKER, 1998.

117 FIGUEROA-PEREA, 2003, p. 17 homem. ${ }^{113}$ No seu entender, muitas vezes usam discursos politicamente corretos e renegam qualquer possibilidade de ter direitos. ${ }^{114}$

O autor observa características da perspectiva de gênero nas duas últimas concepções, contudo, com aportes diferentes de análise. Na quarta, os homens são entendidos a partir da perspectiva das desigualdades de gênero inscritas pelo patriarcado, que fundamentam os processos de desigualdades de gênero de forma global. Essa abordagem constata formalmente que o sistema patriarcal é multidimensional e, por fim, tem formas de controle e de reprodução tão complexas que termina por paralisar qualquer possibilidade e intento de transformação. ${ }^{115}$

A quinta noção adota "uma leitura que historiciza as normas" e propõe-se a definir, problematizar e desconstruir as influências sociais em contextos específicos. ${ }^{116}$ Parte-se da idéia de que, se os homens tomarem consciência das relações de poder, torna-se possível transformá-las e reconstruí-las. Figueroa-Perea filia-se mais a esta última vertente na medida em ela possibilita, a partir de um olhar de gênero, decodificar e desconstruir normas.

Em última análise, na visão de Figueroa-Perea, as três primeiras concepções de homens produzidas nesse campo são marcadas por um discurso descritivomaniqueísta que busca, com suas interpretações, uma divisão das pessoas em boas e más, "para ser mais preciso em boas e maus". 117 O segundo grupo emprega leituras analítico-reflexivas, mas se diferenciam nos modelos explicativos: uma está fundamentada na teoria do patriarcado, formulando explicações mais globais, e a outra enfoca suas análises em contextos específicos. Segundo Figueroa-Perea, o problema dessas concepções apriorísticas é que elas podem enviesar as análises dos resultados, gerando a reafirmação constante de conceitos e do próprio modelo explicativo, restringindo a criatividade analítica e a análise sobre mudanças.

Diante dessa análise crítica sobre o 'estado da arte' de estudos e pesquisas sobre homens e masculinidades, especialmente no contexto da sexualidade e reprodução, ratificamos que é preciso romper com modelos explicativos que, via de regra, reafirmam a diferença e que nos permitem somente explicar como ou por que as coisas assim são, mas que não apontam contradições, fissuras, rupturas, brechas, frestas... que nos permitam visualizar caminhos de transformação progressiva e efetiva. Apostamos na necessidade de abrirmos espaço para novas construções teóricas que resgatem o caráter plural, polissêmico e crítico das leituras feministas. 


\section{Referências bibliográficas}

AQUINO, Estela M L. "Gênero e saúde: perfil e tendências da produção científica no Brasil". Revista de Saúde Pública, n. 40 (número especial), p. 121-132, 2006.

ARILHA, Margareth. Masculinidades e gênero: discursos sobre responsabilidade na reprodução. 1999. Dissertação (Mestrado em Psicologia Social) - Pontifícia Universidade Católica de São Paulo.

. O masculino em Conferências e Programas das Nações Unidas: para uma crítica do discurso de gênero. 2005. Tese (Doutorado em Saúde Pública) - Faculdade de Saúde Pública da Universidade de São Paulo.

ARILHA, Margareth; UNBEHAUM, Sandra; MEDRADO, Benedito (Orgs.). Homens e masculinidades: outras palavras. São Paulo: ECOS/Ed. 34, 1998.

ÁVILA, Maria Betânia. "Direitos sexuais e reprodutivos: desafios para as políticas de saúde". Cadernos de Saúde Pública, n. 19, suplemento 2, p. 465-469, 2003.

BADINTER, Elisabeth. Um amor conquistado: o mito do amor materno. Rio de Janeiro: Nova Fronteira, 1985.

. XY. Sobre a identidade masculina. Rio de Janeiro: Nova Fronteira, 1993.

BARBIERI, Teresita. "Sobre la categoría género. Una introducción teórico-metodológica”. In: RODRÍGUES, Regina (Ed.). Fin de siglo: genero y cambio civilizatorio. Santiago: Isis Internacional, 1992. p. 111-128. (Ediciones de las Mujeres, n. 17).

BEATTY, Barbara. "A Vocation from on High: Kindergartning as an Occupation for American Women." In: WARREN, Donald (ed.). American Teachers: Histories of a Profession at Work. New York: Mac Millan, 1989. p. 65-97.

BONETTI, Alinne de L. Não basta ser mulher, tem de ter coragem: uma etnografia sobre gênero, poder, ativismo feminino popular e o campo político feminista de Recife - PE. 2007. Tese (Doutorado em Ciências Sociais) - Instituto de Filosofia e Ciências Humanas, Universidade Estadual de Campinas.

BOURDIEU, Pierre. La domination masculine. Paris: Seuil, 1998.

BUNGE, Mario. La investigación científica. Barcelona: Ariel, 1989.

BUTLER, Judith. "O parentesco é sempre tido como heterossexual?" Cadernos Pagu, n. 21, p. 219-260, 2003a.

- Problemas de gênero: feminismo e subversão da identidade. Rio de Janeiro: Civilização Brasileira, 2003b.

CÁCERES, Carlos. "Afterword: The Production of Knowledge on Sexuality in the Aids Era: Some Issues, Opportunities and Challenges." In: PARKER, Richard, BARBOSA, Regina 
M., and AGGLETON, Peter (eds.). Framing the Sexual Subject: The Politics of Gender, Sexuality, and Power. Berkeley: University of California Press, 2000. p. 241-260.

CARRIGAN, Tim, CONNELL Robert, and JOHN, Lee. "Hard and Heavy: Toward a New Sociology of Masculinity." In: KAUFMAN, Michael (ed.). Beyond Patriarchy: Essays by Men on Pleasure, Power, and Change. Toronto and Nova York: Oxford University Press, 1985. p. 139-192.

CONNELL, R. W. Masculinities. Berkeley: University of California Press, 1995a.

"Políticas da masculinidade". Educação e Realidade, v. 2 , n. 20 , p. 185-206, 1995b.

CONNELL, R. W., HEARN, Jeff, and KIMMEL, Michael. "Introduction." In: KIMMEL, Michael, HEARN, Jeff, and CONNELL, R. W. (eds.). Handbook of Studies on Men and Masculinities. California: Sage Publications, 2005. p. 1-12.

CORRÊA, Sonia; VIANNA, Adriana. "Teoria e práxis em gênero e sexualidade: trânsitos, avanços, dramas e pontos cegos". In: BONETTI, Alinne; FLEISCHER, Soraya (Orgs.). Dossiê "Entre pesquisar e militar: contribuições e limites dos trânsitos entre pesquisa e militância feministas". Brasília: Centro Feminista de Estudos e Assessoria, 2007. p. 5-21.

COSTA, Ana Alice A. "O movimento feminista no Brasil: dinâmicas de uma intervenção política". Gênero, v. 5, n. 2, p. 9-35, 2005.

COSTA, Claudia de L. "O sujeito no feminismo: revisitando os debates". Cadernos Pagu, n. 19, p. 59-90, 2002.

COSTA, Jurandir F. "A construção cultural da diferença dos sexos". Sexualidade, gênero e sociedade, n. 3, p. 1-6, 1995.

COSTA, Rosely G. "Mediando oposições: sobre as críticas aos estudos de masculinidades". In: ALMEIDA, Heloisa B.; COSTA, Rosely G.; RAMIREZ, Martha C.; SOUZA, Érica R. (Orgs.). Gênero em matizes. Bragança Paulista, SP: Ed. da Universidade São Francisco, 2002. p. 213-241.

CUSCHNIR, Luiz. Homens sem máscaras: paixões e segredos dos homens. Rio de Janeiro: Campus, 2002.

DINIZ, Debora; FOLTRAN, Paula. "Gênero e feminismo no Brasil: uma análise da Revista Estudos Feministas". Revista Estudos Feministas, v. 12, número especial, p. 245-253, 2004. DIGBY, Tom (ed.). Men Doing Feminism. Routledge: Londres, 1998.

FIGUEROA-PEREA. Juan Guillermo. "Algunos elementos para interpretar la presencia de los varones en los procesos de salud reproductiva". Cadernos de Saúde Pública, v. 14, suplemento 1, p. 87-96, 1998.

. "La representación social de los varones en estudios sobre masculinidad y reproducción: 'un muestrario de 
reflexiones'”. In: I Seminário Internacional/II Seminário Norte-Nordeste sobre "Homens, Sexualidade e Reproducão: Tempos, Práticas e Vozes", 17-20 junho 2003, Recife. Mimeo.

. "Algunos dilemas éticos y políticos al tratar de definir los derechos reproductivos en la experiencia de los varones". Perspectivas Bioéticas, Buenos Aires, Facultad Latinoamericana de Ciencias Sociales, v. 10, n. 18, p. 53-75, 2005.

FLOOD, Michael. Frequently Asked Questions about ProFeminist Men and Pro-Feminist Men's Politics. Australian National University, 1997. Mimeo.

FONSECA, Claudia. "Política, gênero e sujeito: afinidades com conseqüências". Cadernos Pagu, n. 21, p. 317 325, 2003.

FOUCAULT, Michel. Microfísica do poder. Rio de Janeiro: Graal, 1982.

. Un dialogo sobre el poder y otras conversaciones: alianzas materiales. Buenos Aires: Alianza, 1990.

. A ordem do discurso. São Paulo: Loyola, 1996.

FOX KELLER, Evelyn. "Qual foi o impacto do feminismo na ciência?" Cadernos Pagu, n. 27, p. 13-34, 2006.

FRASER, Nancy. "Mapeando a imaginação feminista: da redistribuição ao reconhecimento e à representação". Revista Estudos Feministas, v. 15, n. 2, p. 291-308, 2007.

GIFFIN, Karen. "A inserção dos homens nos estudos de gênero: contribuições de um sujeito histórico". Ciência e Saúde Coletiva, v. 10, n. 1, p. 47-57, 2005.

GOLDBERG, Anette. "Feminismo no Brasil contemporâneo: o percurso intelectual de um ideário político". BIB - Boletim Informativo e Bibliográfico de Ciências Sociais, n. 28, p. 42-70, 1989.

GOMÁRIZ, Enrique. "Los estudios de género y sus fuentes epistemológicas: periodización y perspectivas". In: RODRÍGUES, Regina (Ed.). Fin de siglo: genero y cambio civilizatorio. Santiago: Isis International, 1992. p. 83-110. (Ediciones de las Mujeres, n. 17).

GREGORI, Maria Filomena. "Relações de violência e erotismo". Cadernos Pagu, n. 20, p. 87-120, 2003.

GROSSI, Miriam Pillar. "Masculinidades: uma revisão teórica". Antropologia em Primeira Mão, v. 75, p. 1-37, 1995. Disponível em: http://www.antropologia.ufsc.br. Acesso em: 25 maio 2008.

HARAWAY, Donna. "Saberes localizados: a questão da ciência para o feminismo e o privilégio da perspectiva parcial". Cadernos Pagu, n. 5, p. 7-41, 1995.

. "'Gênero' para um dicionário marxista: a política sexual de uma palavra". Cadernos Pagu, n. 22, p. 201246, 2004. 
HERNÁNDEZ, Juan Carlos. "Sexualidad masculina y reproducción ¿Qué va decir papá?" In: Coloquio Latinoamericano sobre "Varones, Sexualidad y Reproducción", 1995, Zacatecas, México. Mimeo.

HOUAISS, Antônio. Dicionário Eletrônico Houaiss da Língua Portuguesa. Rio de Janeiro: Objetiva, 2001.

IZQUIERDO, María Jesús. "Uso y abuso del concepto de gênero". In: VILANOVA, Mercedes (Org.). Pensar las diferencias. Barcelona: Promociones y Publicaciones Universitarias, 1994. p. 31-53.

"Los costos ocultos de la masculinidad". La Manzana. Revista Internacional de Estudios sobre Masculinidades, Puebla, México: Benemérita Universidad Autónoma de Puebla, v. I, n. 2, 2006. Disponível em: www.estudiosmasculinidades.buap.mx. Acesso em: 16 mar. 2008.

KAUFMAN, Michael. Beyond Patriarchy: Essays by Men on Pleasure, Power and Patriarchy. Toronto: Oxford University Press, 1987.

KIMMEL, Michael S. (ed.). Changing Men: New Directions in Research on Men and Masculinity. Newbury Park (California), London and New Delhi: Sage Publications, 1987.

LAQUEUR, Thomas W. Inventando o sexo: corpo e gênero dos gregos a Freud. Rio de Janeiro: Relume Dumará, 2001.

LYRA, Jorge. Paternidade adolescente: uma proposta de intervenção. 1997. Dissertação (Mestrado em Psicologia Social) - Pontifícia Universidade Católica de São Paulo.

MARIANO, Silvana A. "O sujeito do feminismo e o pósestruturalismo". Revista Estudos Feministas, n. 13, v. 3, p. 483-505, 2005.

MEDRADO, Benedito. A masculinidade na propaganda televisiva brasileira. 1996. Texto apresentado para exame de qualificação (Mestrado em Psicologia Social) Pontifícia Universidade Católica de São Paulo.

. O masculino na mídia. 1997. Dissertação (Mestrado em Psicologia Social) - Pontifícia Universidade Católica de São Paulo.

MEDRADO, Benedito; LYRA, Jorge. "Produzindo sentidos sobre o masculino: da hegemonia à ética da diversidade". In: ADELMAN, Mirian; SILVESTRIN, Celsi (Orgs.). Coletânea Gênero Plural. Curitiba: UFPR, 2002. p. 63-76.

MEDRADO, Benedito; LYRA, Jorge; Galvão, Karla; NASCIMENTO, Pedro. "Homens por que? Uma leitura da masculinidade a partir de um enfoque de gênero". Perspectivas em Saúde e Direitos Reprodutivos, v. 3, p. 12-16, 2000.

MEDRADO, Benedito; FRANCH, Mônica; LYRA, Jorge; BRITO, Maíra (Orgs.). Homens, tempos, práticas e vozes. Recife: Fages/Papai/Nepo-Unicamp, 2004. 
MINELLO, Nelson. "Masculinidad/es: un concepto en construcción". Nueva Antropología, n. 61, p. 11-30, 2002.

NICHOLSON, Linda. "Interpretando o gênero". Revista Estudos Feministas, v. 8, n. 2, p. 9- 41, 2000.

NOLASCO, Sócrates. O mito da masculinidade. Rio de Janeiro: Rocco, 1993.

. A desconstrução do masculino. Rio de Janeiro: Rocco, 1995.

De Tarzan a Homer Simpson: banalização e violência masculina em sociedades contemporâneas ocidentais. Rio de Janeiro: Rocco, 2001.

OLIVEIRA, Guacira César de. O desafio de transformar o mundo enquanto nos transformamos. Palestra proferida na abertura da terceira edição dos Diálogos Feministas, em janeiro de 2007, às vésperas do VII Fórum Social Mundial, em Nairóbi, Quênia, 2007. Disponível em: www.mujeresdelsur.org.uy/df/df07_guacira.htm. Acesso em: 25 maio 2008.

OLIVEIRA, Maria Coleta; BILAC, Elizabete; MUSZKAT, Malvina. "It's Not My Fault I Was't Born a Woman": Contraception among Middle-Class Brazilian Men. 2000. Mimeo.

OLIVEIRA, Pedro P. "Crises, valores e vivências da masculinidade". Novos Estudos CEBRAP, n. 56, p. 89-110, 2000.

PARKER, Richard. "Sexualidades masculinas". Conferência no Simposio Latinoamericano sobre Participación Masculina en la Salud Sexual y Reproductiva, 1998, Oaxaca, México. Mimeo.

PARKER, Richard G., and GAGNON, John H. Conceiving Sexuality: Approaches to Sex Research in a Postmodern World. New York and London: Routledge, 1995.

PARRINI, Rodrigo. ¿Existe la masculinidad? Sobre un dispositivo de saber/poder. México: Colégio do México, 2006. Disponível em: http://generomexico.colmex.mx/Parrini.jsp. Acesso em: 9 mar. 2008.

PISCITELLI, Adriana. "Re-criando a (categoria) mulher". In: ALGRANTI, Leila M. (Org.). A prática feminista e o conceito de gênero. Campinas: IFCH-Unicamp, 2002. p. 7-42. (Textos Didáticos, v. 48).

."Reflexões em torno do gênero e feminismo". In: COSTA, Claudia L.; SCHIMIDT, Simone P. Poéticas e políticas feministas. Florianópolis: Mulheres, 2004. p. 43-66.

ROSEMBERG, Fúlvia. "Teorias de gênero e subordinação de idade: um ensaio". Pro-Posições, v. 7, n. 3, p. 17-23, 1997.

"A avaliação de programas, indicadores e projetos em educação infantil". Revista Brasileira de Educação, n. 16, p. 19-26, 2001.

. "Organizações multilaterais, estado e políticas de educação infantil". Cadernos de Pesquisa, n. 115, p. 25-63, 2002. 
RUBIN, Gayle. "El tráfico de mujeres: notas sobre la economía política del sexo". Nueva Antropología, México D.F., v. VII, n. 30, p. 157-209, 1986.

RUBIN, Gayle; BUTLER, Judith. "Tráfico sexual: entrevista". Cadernos Pagu, n. 21, p. 157-209, 2003.

$\mathrm{SABO}$, Don. Comprender la salud de los hombres: un enfoque relational y sensible al género. Boston: OPAS; OMS; Harvard Center for Population and Development Studies, 2000. (Publicacion ocasional: género, equidad, salud, n. 4).

SARTI, Cynthia Andersen. "O feminismo brasileiro desde os anos 1970: revisitando uma trajetória". Revista Estudos Feministas, v. 12, n. 2, p. 35-50, 2004.

SCAVONE, Lucila. "Estudos de gênero e feministas: um campo científico?" In: XXXI Encontro Anual da ANPOCS, 2007, Caxambu, São Paulo. Disponível em: http://201.48.149.89/ anpocs/arquivos/17_10_2007_15_21_39.pdf. Acesso em: 25 maio 2008.

SCOT, Joan W. "Gênero: uma categoria útil para análise histórica". Educação \& Realidade, v. 20, n. 2, p. 71-99, 1995.

STOLCKE, Verena. "¿El sexo es para el género como la raza es para la etnicidad?" Mientras Tanto, Barcelona, n. 48, p. 87-111, 1992.

. "El sexo de la biotecnología". In: DURÁN, Alicia; RIECHMANN, Jorge (Coords.). Genes en el laboratorio y en la fábrica. Madrid: Editorial Trotta, 1998. p. 99-118.

. "Pósfacio: o negócio das diferenças". In: ALMEIDA, Heloisa B.; COSTA, Rosely G.; RAMIREZ, Martha C.; SOUZA, Érica R. (Orgs.). Gênero em matizes. Bragança Paulista: Ed. da Universidade São Francisco, 2002. p. 399-407.

. "La mujer es puro cuento: la cultura del género". Revista Estudos Feministas, v. 12, n. 2, p. 77-105, 2004.

. "O enigma das interseções: classe, 'raça', sexo, sexualidade: a formação dos impérios transatlânticos do século XVI ao XIX". Revista Estudos Feministas, n. 14, v. 1, p. 15-42, 2006.

STRATHERN, Marilyn. "An Awkward Relationship: The Case of Feminism and Anthropology." SIGNS, v. 12, n. 2, p. 276292, 1987.

VALDÉS, Teresa; OLAVARRÍA, José (Orgs.). Masculinidades y equidad de género en América Latina. Santiago, Chile: FLACSO/UNFPA, 1998. p. 12-36.

VALE DE ALMEIDA, Miguel. "Introdução". In: VALE DE ALMEIDA, Miguel. Senhores de si: uma interpretação antropológica da masculinidade. Lisboa: Fim de Século, 1995. p. 1320.

. "Gênero, masculinidade e poder: revendo um caso do Sul de Portugal". Anuário Antropológico/95, p. 161189, 1996. 
VANCE, Carole S. "A antropologia redescobre a sexualidade: um comentário teórico". Physis - Revista de Saúde Coletiva, v. 5, n. 1, p. 7-31, 1995.

WELZER-LANG, Daniel. "A construção do masculino: dominação das mulheres e homofobia". Revista Estudos Feministas, v. 9, n. 2, p. 460-482, 2001.

[Recebido em maio de 2008 e aceito para publicação em junho de 2008]

\begin{abstract}
Men and Masculinity Studies: A Feminist Framework
Abstract: This article aims at contributing to the studies and researches on men and their masculinity, disclosing a gender conceptual mark, from a matrix that dialogues with feminist productions and is organized on 4 axes: 1. Sex/gender system; 2. Relational dimension; Power traits and 4. Rupture of the binary model translation on political, institutional and social organizational spheres. In order to do that, we have dialogued with contemporary productions which are based on different theoretical references and where gender is adopted as an analytical category, but which have in common (and are defined from) a critical feminist perspective. Based on this matrix, a study analysis on men and their masculinity as far as health, sexuality and reproduction field is concerned was carried out, emphasizing the need to make space for new theoretical constructions that recover the plural, polysemic and critical character of feminist readings.

Key Words: Men; Masculinity; Feminist Theory; Feminism.
\end{abstract}

